\title{
HERMENÊUTICA, CIÊNCIA E SOLIDARIEDADE: ALGUMAS CONSIDERAÇÕES NEOPRAGMÁTICAS ${ }^{1}$
}

Maria Virgínia Machado DAZZANI ${ }^{2}$

Nas Ciências Sociais tanto quanto na Filosofia, tem avançado o movimento de reação contra a idéia de que os estudiosos do homem e da sociedade somente seriam "cientistas" (ou "científicos") se continuassem fiéis ao modelo galileano segundo o qual o vocabulário reducionista, matematizado e "puro" é aplicável nas "atividades científicas" porque não apenas explica os fatos, mas reflete o "verdadeiro modo de ser das coisas". Tal modelo galileano trabalha, sobretudo, com termos "axiologicamente neutros", particularmente concernentes aos valores morais, não subjetivos, puramente descritivos, nos quais possam estabelecer generalizações prognósticas, reservando aos "ideólogos" o trabalho subjetivo e valorativo.

Este movimento de reação contra o modelo galileano, possibilitou o surgimento da idéia de Wilhelm Dilthey (1984) de que devemos aplicar métodos "hermenêuticos", não-galileanos, para uma compreensão científica dos seres humanos e da sociedade. Entretanto Richard Rorty, ao apresentar seu pragmatismo, avança um pouco mais, propondo que toda idéia de cientificidade ou de eleição entre métodos parece sempre "confusa", seja nos termos para as Ciências Sociais ou para a Filosofia. Segundo ele, não há sentido em perguntar se os cientistas sociais devem escolher entre a neutralidade axiológica e a interpretação subjetiva, mais ampla ou mais “branda”. Essa pergunta, outrossim, deveria ser definitivamente descartada (RORTY: 1991a, p.191).

Rorty interpretou a herança da Hermenêutica de modo diferente, por exemplo, do de Dilthey (1984) bem como do de Jürgen Habermas 
(1989) e de Karl-Otto Apel (1985). Aos seus olhos, o mérito da Hermenêutica não é oferecer um critério para distinguir as Ciências Naturais das Ciências Humanas. Seu valor é acima de tudo o de desfazer a diferença e a distinção epistemológica entre as várias formas de saber. Ele avalia que a distinção entre Ciências Humanas e Ciências Naturais expressa, na verdade, uma outra diferença mais radical entre cientificidade, letras e artes e práticas humanas em geral. Segundo Rorty, pretender que as formas de saber se distingam ou se conformem a lógicas diferentes expressa o erro de se conceber que o saber "reflete" fielmente o seu objeto. Essa concepção é comumente chamada por ele de "espelho da natureza". Nesta ótica, haveria entre as Ciências Naturais e Ciências Humanas uma distinção que corresponderia à diferença entre "a natureza" e "o espírito", entre "o fato" e "o valor" em que, ao primeiro, estaria associado um conhecimento objetivo e, ao segundo, apenas interpretativo; portanto uma distinção fundamental entre objetividade e interpretação. Mas o mérito da Hermenêutica, principalmente em Hans-Georg Gadamer e Martin Heidegger (e consequentemente em Rorty) foi o de ter mostrado que todo o saber jamais alcança as coisas como elas realmente são; todas as formas de saber são, na verdade, formas de criação de leituras a partir da tradição e da língua e não formas de descoberta (WARNKE: 1991, p.179). É assim que o movimento em favor da conversão das Ciências Sociais à Hermenêutica parece razoável ao pragmatismo, pois narrativas e leis, redescrições e prognósticos são de igual utilidade quando abordamos problemas sociais.

Neste ensaio apresentaremos alguns aspectos da crítica de Rorty à epistemologia, a partir da refutação de um ideal de conhecimento científico objetivo e metodologicamente conduzido. O pragmatismo, segundo Rorty, trata as divisões do mundo em "temas-chave" (subject matters), como recurso possível na tentativa de podermos alcançar o 
que queremos em um certo momento pontual na História usando uma certa linguagem (RORTY: 1991b, p.91). Para tanto, dialogando com a Hermenêutica, Rorty crítica uma perspectiva como a de Dilthey que, segundo Gadamer (1998), permaneceu insistindo na busca de fundamento (Grund) das Ciências do Espírito. Para ele, a Hermenêutica deveria ampliar e renovar a epistemologia e nos libertar da noção de que há um caminho científico e metódico especial para lidar com idéias "filosóficas" em geral (uma noção que John Dewey também insistiu em desaprovar). As divisões rortyanas do mundo não são divisões fundamentais, epistemologicamente distintas. Isto quer dizer que não distinguem-se por qualquer natureza mais ou menos objetiva, mais ou menos correspondente ao mundo. Certamente se estabelecêssemos diferenças de princípio entre o homem e a natureza em termos ontológicos, tornarse-ia justificável a afirmação condutivista de que as diferenças ontológicas ditam uma diferença metodológica no tratamento às questões do homem e da natureza. Mas não é assim que o pragmatismo rortyano (e também deweyano) conduz suas apostas. Ao modo deweyano, portanto, seria menos problemático pensarmos em toda a cultura (abrangendo arte, religião, ciência, literatura, etc.) como uma única atividade, contínua, na qual as divisões em áreas ou "temas-chave" seriam recursos meramente institucionais e pedagógicos (RORTY: 1991b, p.76).

Segundo Rorty, o conhecimento não é algo que possa ser plenamente justificado pela Metodologia Científica, nem é algo que esteja separado das outras práticas humanas como um "discurso privilegiado" (COMETTI: 1995). Assim como a idéia de "verdade", o "conhecimento" é simplesmente um enaltecimento feito às crenças que pensamos estar bem justificadas; as crenças que, momentaneamente, tornam uma segunda justificação desnecessária ou satisfazem o inquérito. Uma investigação sobre a natureza do conhecimento é, na sua concepção, uma 
avaliação histórico-social de como uma comunidade específica tentou alcançar concordância, con-senso (ou seja, uma partilha de sentido) sobre aquilo em que acreditam (RORTY: 1991b, p.24). Dispor de um método significa simplesmente a possibilidade de ordenar nossos pensamentos, nossas hipóteses, inferências e não filtrá-los no intuito de eliminar elementos "subjetivos" e "não-cognitivos" (RORTY: 1991a, p.196). O "conhecimento" enquanto resultado heuristicamente elaborado — tão familiar à Modernidade - é, portanto, a contramão do pragmatismo.

Entre as várias fontes do pragmatismo rortyano - que de uma forma ou de outra conduziram o seu labor - está a herança da Hermenêutica filosófica clássica (como em Dilthey, Heidegger e Gadamer). De certo modo, o pensamento de Rorty está associado ao que é comumente chamado de "giro pragmático-hermenêutico-lingüístico" (BELLO: 1990; MALACHOWSKY: 1990; WARNKE: 1991).

Ora, por Hermenêutica nós entendemos um acontecimento na história do pensamento que, de modo peremptório sustenta que a compreensão humana, como tal, é histórica, lingüística e dialética. (PALMER: 1989, p.214). A Hermenêutica parte do fato de que compreender é estar em relação, no tempo, com a coisa mesma que se manifesta através da tradição. Por outro lado, a compreensão hermenêutica não se dá sem tensões. O caráter estranho e familiar da infinidade de mensagens que são oferecidas pela tradição, historicamente apresentadas em seu sentido e estrutura é que constitui, efetivamente, a tarefa hermenêutica. O problema da Hermenêutica não é a tentativa de explicar um certo estado psicológico do autor, como se verifica em Schleirmacher (In GADAMER: 1997, p.296). Isto quer dizer que não é o traço psicológico que interessa, mas a coisa mesma que é transmitida e pode ser interpretada e compreendida. A Hermenêutica solicita uma posição mediadora entre o caráter estranho e familiar das mensagens. O intérprete confronta-se, inevitavelmente, com o 
seu pertencimento a uma tradição e com sua relação distanciada para com os objetos que constituem o tema das suas pesquisas. Esse caráter oculto e, ao mesmo tempo familiar (heimilich) é que constitui a operação interpretativa, nas palavras de Gadamer (1998, p.67).

Os dois termos nucleares deste acontecimento na história do pensamento são linguagem e historicidade. Segundo Gadamer, de um lado, um ser que pode ser compreendido é linguagem: a Hermenêutica é um encontro com o Ser através da linguagem (PALMER: 1989, p.52). Do outro lado, a consciência que existe é a consciência histórica que, para ser verdadeira e concreta deve considerar a si mesma já como fenômeno essencialmente histórico (GADAMER: 1998, p.70). Vemos em Dilthey que só podemos conhecer numa perspectiva histórica, já que nós mesmos somos seres históricos. Gadamer, por conseguinte, afirma que a superação da ingenuidade natural que nos faz julgar o passado pelas supostas evidências de nossa vida atual e a adoção da perspectiva de nossas instituições, de nossos valores e verdades adquiridos é o ato a partir do qual exercemos o nosso "senso histórico", donde a interpretação é a operação resultante (GADAMER: 1998, p.18).

A consciência histórica já não escuta beatificamente a voz que lhe chega do passado, mas, ao refletir sobre a mesma, recoloca-a no contexto em que ela se originou, a fim de ver o significado e o valor relativos que lhe são próprios. Esse comportamento reflexivo diante da tradição chama-se interpretação. (GADAMER: 1998, p.18-9)

Dilthey defende que a compreensão histórica compreende o ato interpretativo relacionado com as expressões de nossas vidas tal como a obra de arte; enfim, do que é humanamente expressado. Neste ponto, especialmente, reside a relevância da linguagem na obra desse autor porque, segundo ele, "a interioridade humana só na linguagem encontra a sua expressão completa, exaustiva e objetivamente compreensí- 
vel" (DILTHEY: 1984, p.151). Esse ato interpretativo que implica num ato de compreensão histórica seria fundamentalmente distinto da operação de quantificação do modelo galileano. Para Dilthey um ato de compreensão histórica subentende um conhecimento pessoal, individual do que significa sermos humanos. Ele sustenta a necessidade nas Ciências Humanas de uma outra "crítica" da razão; tal crítica faria para a compreensão histórica o que a crítica kantiana da razão pura tinha feito para as Ciências Naturais - uma "crítica da razão histórica" (DILTHEY: 1986, p.39; PALMER: 1989, p.50). Percebemos, portanto, que o esforço de Dilthey em relação às Ciências do Espírito (Geisteswissenschaften) se sustenta, ainda sob a sombra da fundamentação das Ciências Naturais, tendo como referência alguns dos seus princípios como a objetividade e o método.

O grande passo que Heidegger (1998) deu em relação a Dilthey, foi a introdução do princípio segundo o qual a "compreensão" e a "interpretação" são modos fundantes da existência humana e não apenas conseqüência dela. A objetividade e os fundamentos para as Ciências Humanas não estão aqui colocados ao modo diltheyneano. A Hermenêutica heideggeriana do Dasein, transforma-se em Hermenêutica, especialmente na medida em que apresenta uma "ontologia da compreensão". O "Ser-aí" implica em compreensão e interpretação, dando-se no tempo e na linguagem. Parte-se então da compreensão como resultado final para a compreensão e interpretação enquanto condição da existência.

Como podemos verificar, aqui a compreensão é prioritariamente um acontecimento lingüístico. E é sobretudo este ponto que o pragmatismo herda da Hermenêutica. Aquilo que os homens falam de si, do outro, do mundo (nas ciências, nas artes, na política, etc.) só é possível na linguagem. O próprio Rorty (1994, p.26) veio reconhecer que:

$\mathrm{O}$ mundo não fala; nós é que falamos. $\mathrm{O}$ mundo pode ser a causa 
de perfilharmos crenças, uma vez programados com uma linguagem. Não pode, no entanto, propor-nos uma linguagem para falarmos. [...]. A tomada de consciência de que o mundo não nos diz quais os jogos de linguagem que devemos jogar não deveria, no entanto, levar-nos a dizer que uma decisão sobre o jogo que há que jogar é arbitrária, nem a dizer que é a expressão de algo de profundo que existe dentro de nós.

Com esse passo adiante em relação a Dilthey, Heidegger apresenta a linguagem enquanto reveladora do nosso mundo. Esse mundo não é o mundo científico ou ambiente, mas o mundo da vida, pois a linguagem cria a possibilidade do homem poder pertencer a um mundo. Neste sentido, é a linguagem que possibilita o laço social, a existência e o reconhecimento. Pertencer a um mundo é ao mesmo tempo pertencer à linguagem. $\mathrm{O}$ homem partilha suas crenças através da linguagem como mundo e ele próprio existe na linguagem. A experiência não antecede a linguagem, pois a própria experiência ocorre na e pela linguagem. A linguagem é condição. O homem não é anterior à linguagem; outrossim é a linguagem que o constitui. Assim, lingüisticidade e existência se confundem (PALMER: 1989, p.207-10).

Para a hermenêutica gameriana, a linguagem não é, tal como na modernidade, um instrumento de subjetividade, não se realiza na interioridade nem tem um estatuto infinito; pelo contrário, a linguagem é finita e histórica; ela restitui e conduz a experiência do ser no tempo. A linguagem tem que nos levar a compreender o texto: "a tarefa da Hermenêutica é levar a sério a lingüisticidade da linguagem e da experiência e desenvolver uma Hermenêutica verdadeiramente histórica" (PALMER: 1989, p. 215).

Em Verdade e método, Gadamer (1997) tentou mostrar que o processo de confronto entre o velho e o novo, a tradição e o presente permite que o novo venha à luz através do antigo, constituindo, deste modo, 
um processo de "comunicação dialética". É a partir daí que ele toma a pretensão da Hermenêutica à universalidade, onde a linguagem é a base constituidora do homem e da sociedade (FADAMER: 1997, p.14).

Para Gadamer, assim como para Rorty, a principal dificuldade do projeto de uma Hermenêutica Filosófica Geral em Dilthey se encontra no seu esforço de atribuir à natureza dos temas e problemas das Ciências do Espírito a necessidade de uma fundamentação epistemológica, ou seja, atribuir à sociabilidade, à lingüisticidade e à historicidade um estatuto de conceitos científicos, separado, por conseguinte, da condição existencial da vida humana (Idem, 1998, p. 20). As Ciências do Espírito não são apenas mais um desafio para a discussão filosófica; elas são, ao contrário, a constituição de um novo universo de temas e problemas que deverá renovar a Filosofia (até aqui dedicada ao conhecimento da Natureza e do Universo). A experiência histórica, assim como a experiência lingüística, é algo que constitui a própria possibilidade da consciência humana. A consciência humana não é uma inteligência infinita e infalível para a qual o mundo e a realidade se encontram integralmente presentes e definidos. A consciência humana é precária, provisória e contingente porque é uma consciência lingüística e histórica. Nela, a identidade e correspondência absoluta da consciência com o mundo é algo irrealizável (GADAMER: 1998, p.30).

A temporalidade e lingüisticidade em Gadamer são determinantes na compreensão da existência, pois falamos uma língua e somos seres que vivem no tempo, portanto somos seres lingüísticos e históricos. Neste sentido é a lingüisticidade e historicidade do "Ser-aí humano", a sua lembrança e o esquecimento que possibilitam a ressonância e presença do passado e da história na atualidade. A lingüisticidade e historicidade são a memória histórica permanentemente evocada e atualizada. A historicidade, antes danosa ao conceito de Ciência e de Método, 
porque apontava para uma noção "subjetiva" de abordagem do conhecimento situa-se, na Hermenêutica gadameriana, no primeiro plano de uma interrogação fundamental. A historicidade, deste modo, ganha um novo lugar na compreensão da existência (GADAMER: 1998,, p.43).

Podemos ver, ainda em Gadamer, que o conhecimento histórico não pode ser descrito segundo o modelo de um conhecimento objetivista, resultado da investigação metodológica e científica, já que ele mesmo é um processo que possui todas as características de um acontecimento histórico. Mas, ao contrário, a "compreensão" em Gadamer deve ser entendida como um ato da existência - um "projeto lançado", segundo as palavras que ele toma de empréstimo de Heidegger. O objetivismo, desse modo, é uma ilusão. Segundo ele, mesmo como historiadores e representantes de uma Ciência moderna e metódica, somos membros de uma cadeia ininterrupta graças à qual o passado nos interpela e muitas vezes nos invade. Neste sentido, a consciência ética é, ao mesmo tempo, saber ético e ser ético. E agir eticamente é não esquecer o pertencimento a uma tradição (e a essa voz que nos chega de longe): isto seria a base de qualquer consciência histórica (GADAMER: 1998, p.58). Podemos notar que esse caráter ético gadameriano da experiência, da conduta e da consciência, se aproxima - mesmo que de modo turvo - das preocupações rortyanas e das suas margens. Tal preocupação pode ser verificada em alguns de seus recentes ensaios, onde Rorty (1998a) atribui à ética um papel essencial na condução do seu pragmatismo.

Rorty (1991b, p.21) salienta que a nossa tradição cultural ocidental ${ }^{3}$ (que remonta aos gregos e atravessa o período iluminista) centrada na noção de busca pela verdade, é o melhor exemplo da tentativa de encontrar um sentido para a existência a partir do abandono da solidariedade em direção à objetividade. A idéia de verdade como algo que seduz, orientando nossas inquietações, nossas investigações, que tem a si pró-

3. Rorty dedica seu mais célebre trabalho Philosophy and the mirror of nature à construção crítica dessa tradição filosófica (Rorty, 1988a, passim; Malachowiski, 1990, passim). 
pria como causa, sem nenhum sentido de solidariedade para uma comunidade real ou imaginária, é o tema norteador dessa tradição.

Nós somos os herdeiros dessa tradição objetivista, centrada na assunção de que nós precisamos nos manter fora de nossa sociedade, o tempo que for necessário, para examiná-la sob a luz de algo que a transcenda; ou seja, sob a luz disso que ela tem em comum com toda e qualquer outra comunidade humana possível e atual. Essa tradição sonha com uma comunidade derradeira que terá transcendido a distinção entre o natural e o social, que exibirá uma solidariedade que não é paroquial porque é a expressão de uma natureza humana a-histórica. (RORTY: 1991, p.22)

Rorty procura resolver, na sua obra, um dos impasses fundamentais do pensamento pragmatista que tem oscilado, segundo ele, "entre a tentativa de elevar o resto da cultura para o nível epistemológico das Ciências Naturais e a tentativa de puxar o nível das Ciências Naturais para baixo, até elas se tornarem o par epistemológico da arte, da religião e da política" (RORTY: 1991, p.63). A distinção entre o objetivo e o subjetivo foi designada paralelamente à distinção entre fato e valor, Ciências Naturais e Ciências Sociais na tentativa de apresentá-las como dualismos inúteis. Discutir sobre a prioridade, habilidade, objetividade, precisão de qualquer uma sobre a outra (ou qualquer traço que as distinga fundamentalmente) não traz nenhum avanço. $\mathrm{O}$ que está em causa no pragmatismo assinado por Dewey e Rorty não é a afirmação ou crença de que os filósofos ou críticos literários são melhores no que concerne a pensar criticamente, ou a empreender visões amplas e extensas das coisas, do que os teóricos da física, chamados de cientistas "naturais" (aqueles que fazem ciência "dura"), por exemplo. O que está em causa, sobretudo, é o sentido de solidariedade: do que é possível empreender e fazer pela comunidade de pertencimento para que seja mais livre e para 
que possa ampliar o sentido de esperança social. Não importa em que tipo de investigação ou de comunidade de pertencimento esteja envolvida. Esse "fazer" diz respeito à uma operação prático-discursiva, democrática, onde a "conversação" é o ponto de tensão e de cooperação, de engrenagem e de constrição. Neste sentido, a comunidade, de acordo com Rorty, tende a ignorar essas espécies de retórica que não trazem nenhum avanço deixando de lado essas disputas inúteis. O pragmatismo rortyano e deweyano trata as humanidades como estando no mesmo nível da arte e pensa em ambas como fornecendo "antes prazer do que verdade" (Rorty, 1991b, p. 36). Neste aspecto em especial, Rorty (1993, passim) recorre a Heidegger e a sua "poética" para fazer valer a literatura e poesia como saída possível a esses impasses. Se tratarmos qualquer "tema-chave" como tratamos a poesia, diz Rorty, torna-se mais fácil introduzir qualquer metáfora, redescrever e ampliar o modo de ver as coisas (Idem, 1991b, p. 36 seq.).

Estas distinções tão comuns no discurso da modernidade entre fatos sólidos e valores flexíveis, experiência e natureza, verdade e prazer, objetividade e subjetividade, são instrumentos ineficazes, pois elas não são adequadas para dividir a cultura; mas, ao contrário, elas criam mais dificuldades do que resolvem. Tanto Rorty quanto Dewey vêem estas distinções formas dialeticamente menores de um dualismo maior, a saber, "o âmbito do sagrado" versus "o âmbito do destino, do acaso", o âmbito do duradouro e o âmbito do dia-a-dia, contingente. A ciência moderna se aproxima da teologia tradicional no sentido de promover a perpetuação do isolamento do homem e da experiência da natureza. E a intenção de perpetuação é viabilizado justamente pela utilização do vocabulário que se pretende "Próprio à Natureza". Para ambos os autores, o melhor seria encontrar outro vocabulário e recomeçar, "urbanizar" o discurso num outro tom. No entanto, para fazermos isso, temos que 
primeiro encontrar um novo modo de descrição das Ciências Naturais, considerá-la como mais uma narrativa oferecida por uma comunidade específica. Não é uma questão de exceder ou aviltar o cientista natural, mas simplesmente deixar de vê-lo como um sacerdote, desmistificá-lo. O pragmatista sugere que modifiquemos a imagem que temos da ciência e do cientista, ou seja, em vez de um lugar sobre-humano, um lugar também habitado pelas diversas práticas sociais (RORTY: 1991b, p.36). Precisamos parar de pensar numa natureza a-histórica, não-contingente, na objetividade como princípio; devemos ampliar nosso sentido de solidariedade e cooperação, de tolerância e de contingência à Epistemologia. Dewey e Rorty preferem pensar na idéia de que o homem pode aprender com sua história, a partir das narrativas descritas por seus pais, seus avós, por exemplo; sem nenhum determinismo. O pragmatismo parte da concepção darwiniana, naturalizada do mundo. Pensa do mesmo modo que Darwin - nos seres humanos como produtos fortuitos da evolução. Desse modo, não há sentido em distinguir qualquer "ciência" recorrendo a qualquer argumento essencialista ou realista.

Rorty resgata Heidegger ainda para corroborar na sua construção crítica à noção de objetivismo e verdade enquanto correspondência. Em muitos dos seus ensaios evoca um Heidegger para quem o melhor da filosofia reside na eliminação do que impede nossa felicidade, e não o descobrimento de uma representação correta da realidade ${ }^{4}$.

O coração do pragmatismo rortyano é a tentativa de substituir a noção de crenças verdadeiras enquanto "representações da natureza das coisas" e, ao invés disso, pensar em crenças como "regras preditivas de ação". Desse modo, Rorty imagina ser mais fácil sugerir um procedimento empírico, falível, que dê conta de alguns prognósticos, que oriente a conduta, mas pensa ser difícil imaginar um método que dê corpo a esse modo de agir. Método aqui diz respeito a todo apelo que essa pala-

4. Certamente Rorty evoca também um Heidegger que se distancia do que ele chama de "esperança social" — fio condutor do pragmatismo - para tecer severas críticas. Para uma leitura mais aprofundada sobre a crítica rortyana dirigida a Heidegger consultar Rorty (1993, p. $15-121)$. 
vra faz ao discurso da Ciência, do qual o pragmatismo propõe abdicar (RORTY: 1991b, p.65-6).

Rorty insistirá que o desejo de uma Teoria do Conhecimento é o desejo de um "constrangimento" - um desejo de encontrar "fundamentos" a que nos pudéssemos ligar, "quadros para além dos quais nos não devêssemos perder, objetos que se impõem a si mesmo, representação que não pudessem ser negadas" (RORTY: 1988a, p.247-8). Ele toma de empréstimo de Nietzsche a expressão "conforto metafísico" para indicar esse desejo pela fundamentação epistemológica e pela objetividade. O "conforto metafísico" é o engodo da modernidade do qual adverte agora Rorty; é o conforto de pensarmos em nós mesmos como seres infinitos e não contingentes, é a herança da promessa cristã. E é contra esse "conforto" que nos acomoda frente à vida, ao vocabulário, às relações sociais que Rorty oferece suas "redescrições" e "metáforas". Ele não propõe uma saída metodológica ou epistemológica de qualquer espécie. Nas interpretações que ele oferece, "hermenêutica" não é o nome de uma disciplina, nem de um método de atingir o tipo de resultados que a epistemologia não conseguiu atingir, nem de um programa de pesquisa. De outro modo, a hermenêutica deve ser uma expressão de esperança de que o posto até então ocupado pela Epistemologia não seja preenchido - "em que a nossa cultura se deva tornar uma cultura em que já não seja sentida a procura de constrangimento e confrontação" (RORTY: 1988a, p.247-8). A noção de que existe um quadro neutro permanente cuja "estrutura" pode ser exposta pela filosofia é a noção de que os objetos a serem confrontados pela mente, ou as regras que constrangem o inquérito, são comuns a todo o discurso, ou pelo menos a cada discurso sobre um dado tema ou assunto. Deste modo, a epistemologia prossegue na crença e assunção de que todas as contribuições para um dado discurso são comensuráveis, quantificáveis (RORTY: 1988a,

5. Para uma leitura complementar consultar Rorty (1998b). 
p.247-8). A hermenêutica é, em boa medida, uma tentativa de oposição a esta proposição e o pragmatismo assume essa oposição como proposta, redescrevendo inclusive a idéia de comensurabilidade (RORTY: 1988a, p.257) como a possibilidade de reunião de um conjunto de regras que nos oriente no sentido de alcançarmos um acordo racional acerca do que provoca conflito e dúvidas (RORTY: 1988a, p.247-8).

A noção dominante de epistemologia é que para sermos racionais, para sermos completamente humanos, para fazermos o que devemos, precisamos de ser capazes de arranjar um acordo com outros seres humanos. Construir uma epistemologia é encontrar a quantidade máxima de terreno comum com os outros. (RORTY: 1988a, p.248)

A Hermenêutica, de mirada rortyana, vê as relações entre vários discursos como as dos fios numa possível "conversação"; uma conversação que não pretenda se sustentar sobre uma base disciplinar que defina o lugar e as competências dos locutores; mas, ao contrário, uma conversação onde nunca se perde a esperança de acordo. Esta esperança não é a esperança da descoberta de um solo comum anteriormente existente, mas simplesmente a esperança de acordo, ou pelo menos, de desacordo excitante e que de algum modo provoque conseqüências frutíferas. A Hermenêutica trata-os como unidos e próximos naquilo a que ele chama uma societas - pessoas cujos caminhos pela vida se encontraram, unidas muito mais pela civilidade do que por um objeto comum ou por um solo comum. E sobre a idéia de "conversação" a Epistemologia e a Hermenêutica se distinguem radicalmente pois, nas palavras rortyanas, "para a epistemologia a conversação é inquérito implícito e para a hermenêutica, o inquérito é conversação de rotina" (RORTY: 1988a, p.249-50).

Deste ponto de vista, portanto, a linha entre os respectivos domínios da Epistemologia e da Hermenêutica não é uma questão de diferença entre as "Ciências da Natureza" e a "Ciências do Homem", nem entre 
fato e valor, nem entre o teorético e o prático, nem entre o "conhecimento objetivo" e algo mais escorregadio, mais frágil e mais dúbio. Isto significa que somente podemos obter comensuração epistemológica onde já tivermos acordado práticas de inquérito (ou, de um modo mais geral, de discurso), onde já tivermos alcançado um vocabulário comum onde os parceiros se reconheçam (RORTY: 1988a, p.251-2).

A Hermenêutica não é "outra maneira de conhecer" - "compreender" como oposto à (previsiva) "explicação". Contrariamente, a Hermenêutica é antes outra forma de perceber o universo de problemas e tensões. Seguramente, não faz distinções entre a compreensão, explicação e interpretação. Rorty acredita que contribuiria para a clareza filosófica se déssemos simplesmente a noção de "cognição" à ciência prognóstica e parássemos de nos preocupar com "métodos cognitivos alternativos". Em sua análise, a palavra conhecimento não pareceria ser digna de disputa se não fosse a tradição kantiana de que ser um filósofo é possuir uma "teoria do conhecimento" e a tradição platônica de que a ação que não se baseia no conhecimento da verdade de proposições é "irracional" (RORTY: 1988a, p.276).

Segundo Rorty (1991b, p.28-9), o pragmático admite que não possui nenhum ponto de partida a-histórico, através do qual apoia os hábitos das democracias modernas que ele elogia e mesmo participa. Essas conseqüências e asserções são justamente o que desejam e esperam os partidários da solidariedade. Mas dentre os partidários da objetividade, elas provocam, mais uma vez, o temor do dilema formado pelo etnocentrismo por um lado e pelo relativismo do outro. Torna-se muito claro, portanto, na leitura da obra rortyana, a crença de que devemos estabelecer um privilégio especial ("privilégio" aqui não diz respeito à nenhuma fundamentação epistemológica, mas moral) para a nossa própria comunidade (e, no caso especial de Rorty, para a comunidade democrático- 
liberal americana), ou corremos o risco de pretendermos uma tolerância impossível de todos os outros grupos ${ }^{6}$. Essa é sua posição frente ao etnocentrismo e seu posicionamento frente às outras culturas. Afirma, com toda eloquência, que deveríamos ser francamente mais etnocêntricos e menos pretendidamente universalistas, mesmo que essa posição implique em críticas severas por parte de outras comunidades pois — utilizando suas palavras - seu etnocentrismo não tem o "dever" de justificar tudo. Essa posição é, basicamente, a de um Rorty "irônico público liberal" (RORTY: 1991b, p.203; RORTY: 1994, passim; RORTY, DERRIDA et al: 1998).

A esperança rortyana é manter a "conversação" como um objetivo suficiente para a filosofia, onde a sabedoria consiste na capacidade de sustentar e preservar essa conversação. Assim, imagina Rorty, podemos ver os seres humanos como criadores, geradores, inventores daquilo que ele chama "redescrições" ao invés de vê-los como seres capazes de serem exatamente descritos. Por essa razão, nem mesmo dizendo que o homem é sujeito e ao mesmo tempo objeto por si ou em si, estamos a apreender a sua essência (RORTY; 1988a, p.292).

Quando sugerimos que uma das poucas coisas que sabemos (ou necessitamos saber) acerca da verdade é que ela é algo que se conquista em um encontro livre e aberto, nós somos avisados de que definimos 'verdade' como 'a satisfação dos padrões de nossa comunidade'. Mas nós, pragmáticos, não sustentamos esse ponto de vista relativista. Não inferimos de 'não há nenhuma forma racional para justificar comunidades liberais frente a comunidades totalitárias'. Pois essa inferência envolve justamente a noção de 'racionalidade' como um conjunto de princípios a-históricos, a noção que os pragmáticos abjuram. O que nós de fato inferimos é que não há nenhuma forma de bater os totalitários com argumentos, apelando para premissas comuns compartilhados, e

6. Rorty publicou, recentemente, na Folha de São Paulo, o artigo "O futuro da utopia" onde apresenta a relevância da utopia enquanto sonho de um mundo melhor e igualitário frente ao "esnobismo do pensamento pós-moderno” (RORTY: 1999, p.5). 
nenhum sentido, em pretender que uma natureza humana comum faça com que os totalitários, inconscientemente, sustentam tais premissas. (RORTY: 1991b, p.42)

Em Objectivity, relativism and truth, Rorty (1991b, p.2-3) procura fazer a distinção entre o representacionalismo e anti-representacionalismo, descartando a noção de "realismo" e "anti-realismo", argumentando que esta questão diz respeito aos representacionalistas e não aos "anti-representacionalistas". Essa escolha de se manter fora das discussões dessa ordem é coerente com o modo como constrói seu pragmatismo. Ele utiliza, ainda a noção — já referida neste ensaio — de etnocentrismo como um elo entre anti-representacionalismo e liberalismo político. Pois, segundo ele, a cultura liberal dos últimos tempos, encontrou uma estratégia para evitar a desvantagem do etnocentrismo que foi justamente a abertura para o encontro com outras culturas atuais e possíveis, e a ação de tornar essa abertura o ponto central para a sua auto-imagem, como vemos na idéia de globalização. O etnocentrismo é o elo que permite enfrentar o "outro", "a outra cultura" como possibilidade de enfrentamento da própria cultura de origem. Segundo Rorty, esta cultura "é o etnos que se orgulha de si mesmo por sua suspeição frente ao etnocentrismo- antes por sua habilidade em incrementar a liberdade e a abertura dos encontros do que por sua possessão da verdade" (RORTY: 1991b, p.2). Pois aqui o enfrentamento com qualquer comunidade não se dá nos limites da epistemologia, mas nos limites da interpretação e da tolerância.

Meu próprio ponto de vista é o de que não há muito proveito em apontar as 'contradições internas' de uma prática social ou em 'desconstruí-la', a não ser que se possa advir com uma prática alternativa - a não ser que se possa por fim traçar uma utopia, na qual o conceito ou distinção se tornariam obsoletos. Antes de tudo, toda prática social de alguma complexidade, assim como todo e qualquer elemento de uma tal 
prática, contém tensões internas. (RORTY: 1991b, p.16)

Os pragmáticos querem substituir a idéia de "objetividade" pela de "concordância não-forçada". Esta última refere-se a "nós", um "nós" etnocêntrico. Para Rorty, nós sempre podemos ampliar os "nossos" escopos observando outras pessoas ou culturas como membros ou representantes, tanto quanto nós mesmos, de alguma comunidade de investigação - tratando-os enquanto partes de um grupo, no interior do qual a concordância não-forçada deve ser buscada. $\mathrm{O}$ que não podemos fazer é nos lançar para além de todas as comunidades humanas numa incursão a-histórica e finita, não contingente, não etnocêntrica. Essa passagem diz respeito justamente a porção de filiação à tradição, costumes e valores que sempre nos interpela. Negar essa porção é negar os próprios limites. A democracia, nesse contexto, se inscreve como elemento que permite esse encontro sempre precipitado, que possibilita a "conversação" e o "acordo".

A "conversação" e o "acordo" como possibilidades viabilizadas pela democracia não acontece certamente sem as devidas tensões; disso o próprio Rorty está advertido. O pragmatismo não se vê iludido frente aos limites (da Linguagem, do Homem, da vida, etc.). Poderíamos até arriscar que - utilizando o jargão psicanalítico — o pragmatismo está advertido da sua castração, mas nem por isso desiste da causa que toma como sua. A valorização e prioridade rortyana das práticas democráticas e liberais sobre qualquer outra e do confronto livre e aberto para negociações é profundamente atacado por alguns dos seus críticos. De certo modo, Rorty é considerado, às vezes, apenas mais um democrata liberal americano, ou um relativista pretensioso ${ }^{7}$. De qualquer maneira, suas posições políticas, práticas, discursivas são afinadas com posições deweyanas de igual dimensão onde a contingência, historicidade, ironia pública, solidariedade assumem um caráter norteador frente a ou- 
tras práticas justificando, quando possível, cada escolha. $\mathrm{O}$ traço marcadamente etnocêntrico o faz falar a partir do lugar que lhe parece mais justo, mais próximo da possibilidade do exercício dessas práticas que tanto acalenta (solidariedade, tolerância, democracia). Certamente, seu pragmatismo não oferece nenhuma garantia, nenhuma saída fácil frente às dificuldades mais urgentes como a fome, a miséria, os regimes autoritários e perversos, a loucura, a morte, etc. Seu pragmatismo é uma aposta na esperança social, sem qualquer fundamentação objetiva ou ahistórica. Para ele, é possível apostar em tais práticas por uma condição de solidariedade não fundamentada em qualquer proposição científica, objetivamente válida ou qualquer versão humanista-cristã dos seres hu$\operatorname{manos}^{8}$ (RORTY: 1991b, p.59).

Da perspectiva de um discurso que acolha o pensamento de Wittgenstein, Dewey e Donald Davidson, não é possível se falar de uma teoria ou de uma descrição que seja, por si só, a "melhor explicação" do mundo. Como podemos encontrar nestes autores citados, mas também em William James, uma explicação sobre a natureza das coisas é o que é conveniente e útil aos nossos interesses e responde às nossas crenças (JAMES, 1995). Uma explicação (científica, religiosa ou cotidiana) sempre será uma descrição que, obrigatoriamente, deverá conviver com inúmeras outras descrições alternativas. Como afirma Hilary Putnam (1992, p. 45), não podemos falar do ponto de vista do olho de Deus; não há qualquer descrição que seja “mais próxima” do mundo (RORTY: 1991b, p.60).

Deste modo não temos, conclui Rorty, uma linguagem que sirva como base neutra permanente para formular todas as boas hipóteses explicativas ou a melhor chave interpretativa. Uma linguagem para observar o mundo diretamente, mas que seja neutra em relação às nossas perspectivas e interesses, é simplesmente inútil. Assim, segue ele, é improvável que a epistemologia - como tentativa para tornar todos os 
discursos comensuráveis, quantificáveis por meio da tradução para um conjunto estipulado de termos - seja uma saída satisfatória e útil (RORTY: 1988a, p.271).

Rorty prefere não falar de uma "nova ciência social", mas de "esperança social" onde o fulcro é efetuar a função social a que Dewey chamou "quebrar a crosta da convenção", impedir que o homem se iluda com a noção de que conhece a si próprio, ou a qualquer outra coisa, exceto sob descrições opcionais (RORTY, 1988a: p.293.) Ele pensa que colocando a questão em termos políticos e morais, ao invés de colocá-los em termos epistemológicos ou metafísicos, deixa as coisas mais claras. É uma questão de escolha de princípio e não o modo segundo o qual se definem palavras como "verdade", "racionalidade", "conhecimento" ou "filosofia". O problema gira em torno de que auto-imagem nossa sociedade deveria ter de si mesma. Quando se diz que há "uma necessidade de se evitar o relativismo" isso é, no máximo, justificável como um esforço de manter certos hábitos concernente ao modo de vida do homem europeu:

Esses eram os hábitos nutridos e justificados pelo Iluminismo em termos de um apelo à razão, concebida enquanto uma capacidade humana transcultural de corresponder à realidade, uma faculdade cuja possessão e uso são demonstrados pela obediência a critérios explícitos. Assim, a verdadeira questão sobre o relativismo é se esses mesmos hábitos de vida intelectual, social e política podem ser justificados por uma concepção de racionalidade enquanto atingindo os seus objetivos sem critérios, e por uma concepção pragmática da verdade. (RORTY: 1991b, p.28)

O pragmático de estirpe rortyana não tem uma teoria da verdade, muito menos uma teoria relativista. Enquanto partidário e adepto da solidariedade, sua avaliação do valor da investigação humana cooperativa e tolerante só possui uma base ética, não uma base epistemológica ou metafísica. Não tendo qualquer epistemologia (ou fundamentação anco- 
rada no conhecimento de cunho epistemológico) ele não possui nenhuma epistemologia relativista (RORTY: 1991b, p.24).

É nestes termos que Rorty elabora sua interpretação da Hermenêutica e, com isso, oferece um dos pontos de inflexão do debate filosófico sobre ciências e, principalmente, sobre os discursos sobre o homem. Para ele, há uma absoluta prioridade das práticas sociais que se inventam e se "criam" (no sentido poético e até heideggeriano do termo) no conflito "aberto" e renovável. Por essas razões, a conclusão que chega pode ser assim definida:

Uma vez que 'educação' é um pouco insípido de mais, e Bildung [educação, autoformação] um pouco estranho de mais, utilizarei 'edificação' para significar este projeto de encontrar novas, melhores, mais interessantes e mais fecundas maneiras de falar. A tentativa de edificar (a nós mesmos ou a outros) pode consistir na atividade hermenêutica de estabelecer ligações entre a nossa própria cultura e qualquer cultura exótica ou período histórico, ou entre a nossa disciplina e uma outra que pareça perseguir fins incomensurável. Mas pode, em vez disso, consistir na atividade 'poética' de projetar esses novos objetivos, novas palavras, ou novas disciplinas, seguida, por assim dizer, pelo inverso da hermenêutica: a tentativa de reinterpretarmos o nosso ambiente familiar nos termos pouco familiares das nossas novas invenções. Em qualquer dos casos, a atividade é (apesar da relação etimológica entre as duas palavras) edificantes sem ser construtiva - pelo menos se 'construtiva' significar o tipo de cooperação na realização de programas de investigação que ocorre no discurso normal. Porque o discurso edificação é suposto ser normal, arrancar-nos para fora do nosso velho eu pelo poder da estranheza, para nos ajudar a tornar novos seres. (RORTY: 1988a, p. 279)

Com isso, Rorty parece reivindicar da Hermenêutica um certo traço que alimenta o espírito de quem não gosta de palavras acostumadas. 


\section{Referências}

APEL, K. O. La transformación de la filosofía: el a priori de la comunidad de comunicación. v 2. Tradução de Adela Cortina et al. Madrid: Taurus, 1985.

BELLO, G. Richard Rorty en la encrucijada de la filosofía postanalítica: entre pragmatismo y hermenéutica. In: RORTY, Richard. El Giro Lingüístico: Dificuldades metafilosóficas de la filosofía lingüística. Barcelona : Ediciones Paidós,1990. p. 9-44.

COMETTI, J. Filosofia sem privilégios. Tradução de Fernando Marinho. Lisboa: Asa, 1995.

DILTHEY, W. Origens da hermenêutica / Plano de continuação da obra. Estruturação do mundo histórico pelas ciências do espírito. Tradução de Alberto Reis. In: AGOSTINHO et al. Textos de hermenêutica. Lisboa: Rés, 1984. p.147-203.

------. Introducción a las ciencias del espíritu: ensayo de una fundamentación del estudio de la sociedad y de la historia. Tradução de Julián Marías. Madrid : Alianza, 1986.

GADAMER, H. Verdade e método. 2ed. Tradução de Flávio Meurer. Petrópolis : Vozes, 1997.

------. O problema da consciência histórica. Tradução de Paulo César Estrada. Rio de Janeiro: Fundação Getúlio Vargas, 1998.

HABERMAS, J. Consciência moral e agir comunicativo. Tradução de Guido de Almeida. Rio de Janeiro: Tempo Brasileiro, 1989.

HEIDEGGER, M. Ser e tempo: parte I. Tradução de Márcia de Sá Cavalcanti. Petrópolis: Vozes, 1988.

HEKMAN, S. J. Hermenêutica e sociologia do conhecimento. Tradução de Luís Manuel Bernardo. Lisboa: Edições 70, 1990.

JAMES, W. Pragmatism. New York: Dover Publicayions, 1995.

MALACHOWSKI, A (Ed.). Reading Rorty: critical responses to Philosophy and the Mirror of Nature (and beyond). Oxford/Cambridge: Blackwell, 1990.

PALMER, R. Hermenêutica. Tradução de Maria Luísa Ferreira. Lisboa: Edições 70, 1989.

PUTNAM, H. Razão, verdade e história. Tradução de António Duarte. Lisboa: Dom Quixote, 1992.

RORTY, R. A filosofia e o espelho da natureza. Tradução de Jorge Pires. Lisboa: Dom Quixote, 1988a.

------. Foucault y la epistemología. Tradução de Bonano. In: HOY, D. C. (Comp.). 
Foucault. Buenos Aires: Nueva Visión, 1988b. p.51-60.

El Giro Lingüístico: Dificuldades metafilosóficas de la filosofía lingüística. Tradução de Gabriel Bello. Barcelona: Ediciones Paidós, 1990.

Consequences of pragmatism (essays: 1972-1980). 5ed. Mineapolis: University of Minnesota, 1991a.

Objectivity, relativism and truth: philosophical papers. v 1. Cambridge: Cambridge University Press, $1991 b$.

Ensaios sobre Heidegger y otros pensadores contemporáneos: escritos filosóficos 2. Tradu ção de Jorge Vigil Rubio. Barcelona: Paidós, 1993.

Contingência, ironia e solidariedade. Tradução de Nuno Ferreira da Fonseca. Lisboa: Presença, 1994.

Derechos humanos, racionalidad y sentimentalismo. Tradução de Ofelia Castillo. In: ABRAHAM, T. et al. Batallas eticas. Buenos Aires: Nueva Visión, 1995. p. 59-80.

------. Pragmatismo y política. Tradução de Rafael del Águila. Barcelona: Paidós, 1998a.

Nietzsche, Sócrates e o pragmatismo. Tradução de Paulo Guiraldelli Jr. In: Cadernos Nietzsche. n 4. São Paulo, 1998b. p.7-15.

------. O futuro da utopia. Tradução de Clara Allain. In: Folha de São Paulo. 04/04/1999.

; DERRIDA, Jacques et al. Desconstrucción y pragmatismo.

Tradução de Marcos Mayer e Inés M. Pousadela. Buenos Aires: Paidós, 1998.

WARNKE, G. L'herméneutique et le 'nouveau pragmatisme'. In: Her méneutique, tradition et raison. Tradução de J. Colson. Bruxelles: De Boeck, 1991. p. 177-208. 